\title{
A Raman-scattering study on the interface structure of nanolayered TiAIN/TiN and TiN/NbN multilayer thin films grown by reactive dc magnetron sputtering
}

\author{
Harish C. Barshilia ${ }^{\text {a) }}$ and K. S. Rajam \\ Surface Engineering Division, National Aerospace Laboratories, Post Bag No. 1779, \\ Bangalore 560 017, India
}

(Received 5 January 2005; accepted 12 May 2005; published online 8 July 2005)

\begin{abstract}
Nanolayered multilayer coatings of TiAlN/TiN and TiN/NbN were deposited on $\mathrm{Si}$ (100) substrates at various modulation wavelengths (i.e., bilayer thickness, $\Lambda$ ) using a reactive dc magnetron sputtering system. These coatings were characterized using micro-Raman spectroscopy to study the effect of interfaces on the optical-phonon modes. For TiAlN/TiN multilayers, the optical-phonon band shifts to higher frequencies with a decrease in the modulation wavelength. Furthermore, the optical-phonon band shifts to higher frequencies with an increase in the substrate temperature for TiAlN/TiN multilayers deposited at $\Lambda=80 \AA$. No such shift was observed for single-layer $\mathrm{TiN}$ and $\mathrm{TiN} / \mathrm{NbN}$ multilayer coatings. This observed shift has been attributed to interdiffusion between the layers during deposition, which is more for TiAlN/TiN multilayers as compared to $\mathrm{TiN} / \mathrm{NbN}$ multilayers. The x-ray-diffraction data showed well-defined satellite reflections for $\mathrm{TiN} / \mathrm{NbN}$ multilayers at low modulation wavelengths and very weak satellite reflections for TiAlN/TiN multilayers, indicating that interfaces were very broad for TiAlN/TiN multilayers. The nanoindentation data showed no significant improvement in the hardness of TiAlN/TiN multilayers as compared to the rule-of-mixture value, whereas $\mathrm{TiN} / \mathrm{NbN}$ multilayers showed an improvement in the hardness, which was two times the rule-of-mixture value. The low hardness of TiAlN/TiN multilayers has been attributed to interfacial diffusion. (C) 2005 American Institute of Physics. [DOI: 10.1063/1.1946193]
\end{abstract}

\section{INTRODUCTION}

In recent years nanolayered multilayer coatings of transition-metal nitrides have received considerable interest due to their exotic properties such as high hardness and toughness at very low bilayer thicknesses (also known as modulation wavelength, $\Lambda$ ). Multilayer coatings of $\mathrm{TiN} / \mathrm{NbN}$ have been studied extensively in the last decade. $\mathrm{TiN} / \mathrm{NbN}$ multilayer coatings exhibit very high hardness, corrosion resistance, and other tribological properties. ${ }^{1-4}$ The incorporation of $\mathrm{Al}$ in the face-centered-cubic TiN structure on Ti sites has led to the development of TiAlN. ${ }^{5}$ TiAlN is a very promising material for wear resistance coatings because of its high-temperature corrosion and oxidation resistance, which results in higher chemical stability, in comparison to TiN. ${ }^{6,7}$ In addition, low thermal conductivity of TiAlN enables higher cutting speeds. However, it has been reported that TiAlN coatings, in general, show poorer performance than TiN in the case of low sliding speed due to brittleness and high friction coefficient. ${ }^{8}$ Multilayer coatings of TiAlN/TiN combine properties of both TiN and TiAlN, and exhibit higher oxidation resistance and wear resistance. ${ }^{8-11}$

Raman spectroscopy has been widely used in the field of composition-modulated semiconductor and amorphous superlattices to study the interface structure, ${ }^{12-18}$ strain, ${ }^{19-22}$ and structural stability. ${ }^{23}$ Raman scattering has also been

\footnotetext{
${ }^{a)}$ Author to whom correspondence should be addressed; FAX: +091-8025210113; electronic mail: harish@css.nal.res.in
}

used to study the quantum wire structures. ${ }^{24,25}$ An excellent review on the Raman spectroscopy of vibrations in semiconductor superlattices has been written by Jusserand and Cardona. ${ }^{26}$ In the field of physical-vapor-deposited (PVD) hard coatings Raman spectroscopy has been used to study oxidation, ${ }^{27,28}$ wear debris, ${ }^{29}$ and stress. ${ }^{30}$ There has been a little work on the Raman spectroscopy studies on the transition-metal nitride-based hard superlattices. ${ }^{28,31}$ This is mainly because of the fact that Raman scattering from materials with metallic properties is restricted by prohibitive selection rules, low penetration depth of the incident light, etc. Recently Constable et al. have used Raman spectroscopy to characterize various single and multicomponent PVD hard coatings $^{32}$ and also to study the stress $\operatorname{state}^{33}$ of TiAlN/VN multilayer coatings. In this paper, we present a comprehensive Raman-scattering study of TiAlN/TiN- and TiN/NbN-nanolayered multilayer coatings. We also present $\mathrm{X}$-ray diffraction (XRD) and nanoindentation data to corroborate the Raman data.

\section{EXPERIMENTAL DETAILS}

Single-layer TiN, TiAlN, and $\mathrm{NbN}$ and multilayer TiAlN/TiN and TiN/NbN films were deposited on silicon (100) substrates using a multitarget reactive dc magnetron sputtering system that has been described in detail elsewhere. ${ }^{1,2,28,34}$ The substrates were chemically cleaned in an ultrasonic agitator in acetone, absolute alcohol, and trichloroethylene. Subsequently, the substrates were cleaned in situ by $\mathrm{Ar}^{+}$-ion bombardment for 30 min wherein a dc 
bias of $-850 \mathrm{~V}$ was applied to the substrate at an argon pressure of $6.0 \times 10^{-1} \mathrm{~Pa}$. TiAlN films were prepared from reactive sputtering of a TiAl (50:50) composite target in Ar $+\mathrm{N}_{2}$ plasma operated at a pressure of $2.0 \times 10^{-1} \mathrm{~Pa}$. TiN and $\mathrm{NbN}$ layers were deposited from the reactive sputtering of $\mathrm{Ti}$ and $\mathrm{Nb}$ targets, respectively. The process parameters were first optimized to achieve $\mathrm{B} 1 \mathrm{NaCl}$ structure of single-phase $\mathrm{TiN}, \mathrm{NbN}$, and TiAlN. Multilayer films with controlled layer thickness and repeatability were deposited using a personal computer (PC)-based dwell time controller. In this system a stepper motor was connected to the substrate holder through a rotary feedthrough and the substrate was rotated back and forth between the two targets to achieve multilayer deposition. For multilayer coatings the individual layer thickness of the two materials was the same. Two sets of coatings were prepared. In the first set, the thickness of the coatings was approximately $1400 \AA$ and these samples were used for Raman measurements. In the second set, the thickness of the coatings was approximately $1.5 \mu \mathrm{m}$ and these samples were used for XRD and nanoindentation measurements. For the second set of samples an approximately $0.5-\mu \mathrm{m}$-thick Ti interlayer was also incorporated to improve the adhesion of the coatings on the substrate. The growth rates were measured by examining the cross section of the coatings in scanning electron microscopy. Unless otherwise specified we used a substrate bias of $-200 \mathrm{~V}$, a substrate temperature of $300{ }^{\circ} \mathrm{C}$, and a nitrogen flow rate of $2.5 \mathrm{SCCM}$ (standard cubic centimeter per minute) for all the coatings.

A Dilor-Jobin-Yvon-Spex integrated Raman spectrometer (Model Labram) was used for the present experiments. ${ }^{28}$ The spectrometer consisted of a microscope coupled confocally to a $300-\mathrm{mm}$ focal length spectrograph equipped with two switchable gratings (300 and 1800 grooves $/ \mathrm{mm}$ ). A HeNe 20-mW laser beam was used as the excitation source. The laser was totally reflected by a notch filter towards the sample under a microscope and the Raman scattering was totally transmitted through the notch filter towards the confocal hole and entrance slit of the spectrometer. The spectrum was recorded in a Peltier-cooled charge coupled device (CCD) detector. The data were collected with a 20-s data point acquisition time in the spectral range of $100-1200 \mathrm{~cm}^{-1}$.

XRD patterns of the films in Bragg-Brentano $\theta-2 \theta$ geometry were recorded in a Rigaku D/max 2200 Ultima x-ray powder diffractometer. The x-ray source was a $\mathrm{Cu} K \alpha$ radiation $(\lambda=1.5418 \AA)$. High-temperature XRD measurements were taken in a $1.2-\mathrm{kW}$ Siemens Kristalloflex diffractometer ( $\mathrm{Cu} K \alpha$ radiation) in Bragg-Brentano $\theta-2 \theta$ geometry. The compositions of the films were determined using energy dispersive $\mathrm{x}$-ray analysis (EDAX) in a scanning electron microscope (Leo 4401). The hardness measurements were performed in a nanoindenter (CSEM Instruments) at a load of $5 \mathrm{mN}$ using a Berkovich diamond indenter. At this load the indentation depth was much less than $1 / 10$ of the film thickness, thus eliminating the effect of substrate on the hardness measurements. Ten indentations were made on each sample and the values reported herein represent the average of ten values.

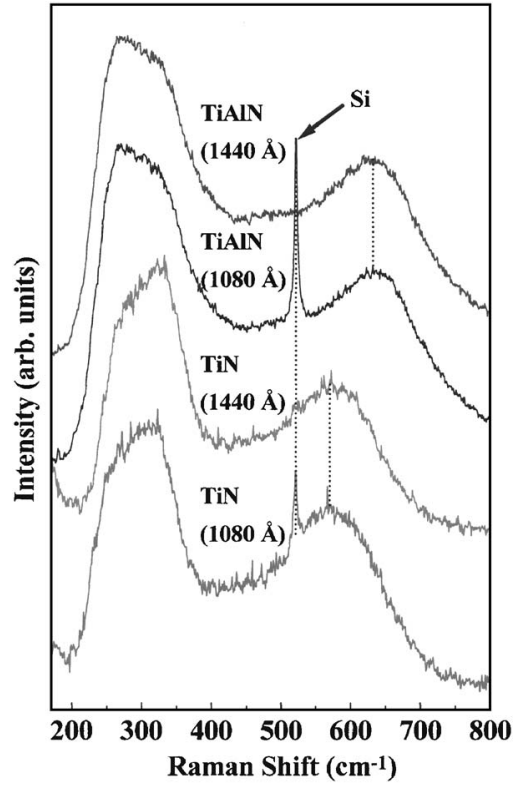

FIG. 1. Raman spectra of approximately 1400- $\AA$-thick as-deposited TiN and TiAlN coatings, indicating the presence of acoustic and optic phonon modes.

\section{RESULTS AND DISCUSSION}

\section{A. Raman spectra of TiAIN/TiN and TiN/NbN multilayers}

In Fig. 1 we plot the Raman spectra of about 1080- and 1440-Å-thick TiN coatings deposited on Si (100) substrates. The spectrum of TiN coating shows two broadbands centered at 292 [full width at half maximum $(\mathrm{FWHM})=46 \mathrm{~cm}^{-1}$ ] and $576 \mathrm{~cm}^{-1}\left(\mathrm{FWHM}=55 \mathrm{~cm}^{-1}\right)$. These bands originate due to acoustic transitions in the $150-300-\mathrm{cm}^{-1}$ region (LA and TA) and optic modes in the $400-650-\mathrm{cm}^{-1}$ region (LO and TO). ${ }^{35}$ Scattering in the acoustic range is primarily determined by the vibrations of the Ti ions and that in the optic range by the vibrations of the $\mathrm{N}$ ions. ${ }^{27}$ The Raman spectrum of TiAlN coating consists of two broadbands centered at 277 $\left(\mathrm{FWHM}=55 \mathrm{~cm}^{-1}\right)$ and $640 \mathrm{~cm}^{-1}\left(\mathrm{FWHM}=69 \mathrm{~cm}^{-1}\right)$. The Raman spectra of TiN and TiAlN are almost similar except that the broadband associated with optical transitions shifts to higher frequencies in the latter case.

In Fig. 1 the Raman peak associated with $\mathrm{Si}$ substrate $\left(520 \mathrm{~cm}^{-1}\right)$ can be clearly seen for the 1080 - $\AA$-thick TiN coating and it disappears if the coating thickness is increased to about $1440 \AA$. This suggests that the penetration depth of the laser beam is about $1400 \AA$ and the Raman data of approximately $1400-\AA$-thick TiN coating provide Raman signal from almost the whole thickness of the coating. Similarly, as shown in Fig. 1, it can be assumed that the penetration depth of the laser beam is approximately $1400 \AA$ for TiAlN coating. For all the subsequent experiments, therefore, we kept a total thickness of about $1400 \AA$ for TiN, TiAlN, and TiAlN/TiN multilayer coatings.

After optimizing the process parameters for the deposition of TiN and TiAlN coatings we deposited multilayer coatings of TiAlN/TiN at different modulation wavelengths. Figure 2 shows the Raman spectra of approximately 1400$\AA$-thick TiAlN/TiN multilayer coatings deposited at various 


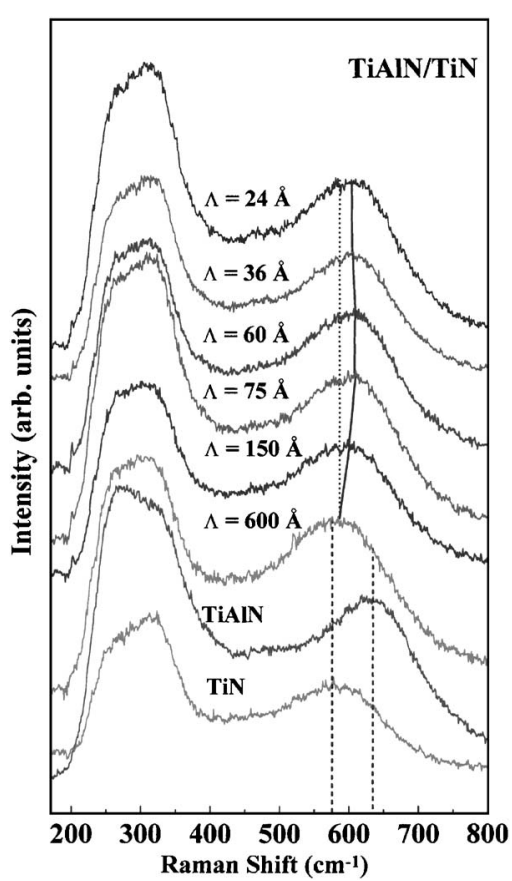

FIG. 2. Raman spectra of approximately 1400- $\AA$-thick TiAlN/TiN multilayer coatings at various modulation wavelengths. Also shown are the Raman spectra of single layer TiN and TiAlN coatings of similar thicknesses. Other process parameters such as substrate temperature, substrate bias, nitrogen flow rate, Al concentration, etc., were same for all the coatings.

modulation wavelengths. Also shown in the figure are the Raman spectra of single-layer TiN and TiAlN coatings of similar thicknesses. The multilayer coatings prepared at $\Lambda$ $=600$ and $24 \AA$ contained 4 and 100 interfaces, respectively. In the case of multilayer coatings as the thicknesses of individual layers are small the Raman contributions from different layers of the multilayer samples are cumulative. The Raman spectrum of as-deposited TiAlN/TiN multilayer coating consists of two broadbands centered at 280 (FWHM $\left.=46 \mathrm{~cm}^{-1}\right)$ and $589 \mathrm{~cm}^{-1}\left(\mathrm{FWHM}=62 \mathrm{~cm}^{-1}\right)$, which is similar to that of TiN. It is interesting to note that the opticalphonon band shifts to higher frequencies with a decrease in the modulation wavelength. This variation is more clearly shown in Fig. 3. Also, shown in Fig. 3 is the variation of the FWHM of the optical-phonon band with $\Lambda$. It is clear that the FHWM does not change significantly with $\Lambda$. It must be pointed out that $\mathrm{Al}$ concentration, nitrogen flow rate, substrate bias, substrate temperature, and total thickness of the coatings were kept the same for all the samples and, therefore, shift in the optical-phonon band with $\Lambda$ cannot be attributed to these parameters.

The shift in the frequency of the optical-phonon mode of TiAlN/TiN multilayers with modulation wavelength might have several causes such as phonon confinement, strain effect, and composition. The phonon confinement effect observed in the nanocrystalline materials is primarily due to relaxation of the phonon wave vector. ${ }^{36,37}$ The phonon confinement leads to a downshift (also called redshift), broadening of the Raman signal, and asymmetry on the lowfrequency side in the optical-phonon band. Therefore, the observed shift in the present study cannot be attributed to the

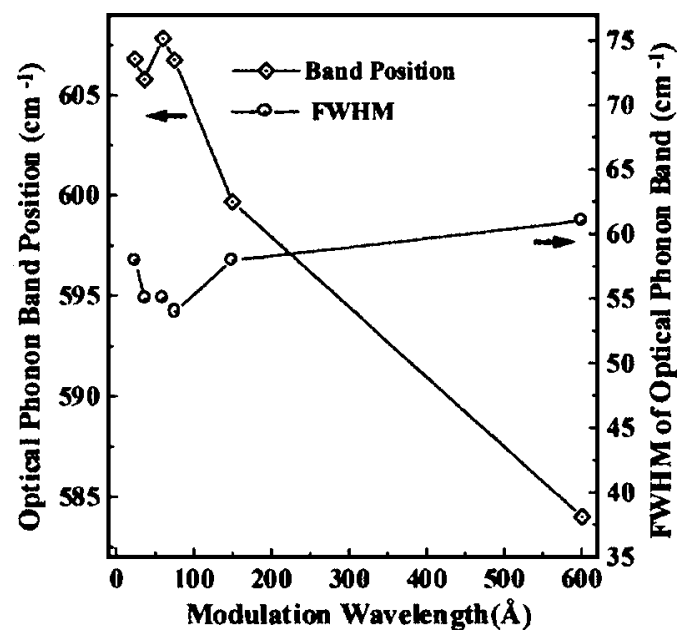

FIG. 3. Variations of position and FWHM of the optic phonon band of TiAlN/TiN multilayer coatings with modulation wavelength.

phonon confinement. Furthermore, for TiAlN/TiN multilayer system, the difference in the lattice spacing is close to zero (approximately $0.4 \%$ ). Therefore, we can assume that the interfacial strain (or coherency strain) is mini$\mathrm{mal}$ in TiAlN/TiN multilayers. Thus, the effect of coherency strain on the observed shift can also be ruled out. To further verify this we have taken another multilayer system (i.e., $\mathrm{TiN} / \mathrm{NbN}$ ) wherein the average misfit is relatively large (approximately 3.6\%). Figure 4 shows the Raman spectra of approximately 1400- $\AA$-thick TiN/NbN multilayers deposited on $\mathrm{Si}(100)$ at various modulation wavelengths. Also,

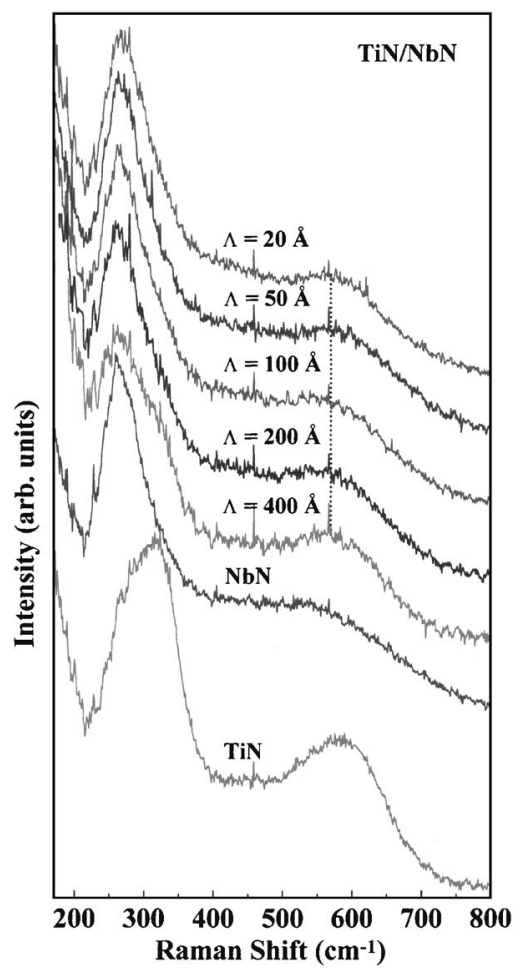

FIG. 4. Raman spectra of approximately $1400-\AA$-thick TiN/NbN multilayer coatings at various modulation wavelengths. Also shown are the Raman spectra of single layer TiN and $\mathrm{NbN}$ coatings of similar thicknesses. Other process parameters such as substrate temperature, substrate bias, nitrogen flow rate, etc., were same for all the coatings. 


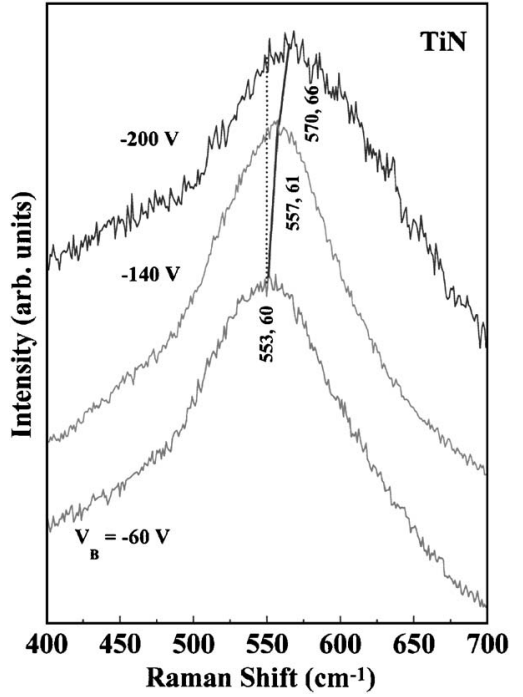

FIG. 5. Raman spectra of TiN coatings deposited at various substrate biases. Other conditions such as substrate temperature, nitrogen flow rate, etc., were same for all the coatings.

shown in the figure are the Raman data of approximately $1400-\AA$-thick TiN and NbN coatings. The optical-phonon band of $\mathrm{NbN}$ is very broad (FWHM $=94 \mathrm{~cm}^{-1}$ ) as compared to TiN and TiAlN. It is interesting to note that there is no significant shift in the position of the optical-phonon band with modulation wavelength. These observations show that coherency strain-induced effects are very difficult to detect in transition-metal nitride superlattices using Raman scattering. One possible reason for this could be due to lack of welldefined and sharp phonon bands in these materials. For example, the first-order Raman scattering of a perfect TiN crystal is forbidden because of $O_{h}$ symmetry. ${ }^{38}$ However, reactive-sputtered titanium nitride coatings contain defects which allow an impurity-induced Raman scattering of the first order.

It is known that ion bombardment of the transition-metal nitride PVD coatings leads to compressive stress. ${ }^{39-41}$ The compressive stress in the PVD hard coatings has been related to $\mathrm{Ar}^{+}$ion bombardment-induced point defects. ${ }^{40}$ The ion bombardment is required to achieve noncolumnar and dense microstructures, reduced crystallite size, and improved adhesion of the coatings. As it has already been pointed out the Raman bands are sensitive to stress levels within the coating via piezospectroscopic effects; band shift to a higher wave number gives a direct measure of the compressive stress levels. ${ }^{30}$ In order to verify the effect of stress on the shift in the position of the optical-phonon band we prepared TiN samples at different substrate biases. We intentionally prepared single-layer TiN coatings instead of multilayer coatings at different bias voltages because of the fact that ion bombardment may affect the interface quality and effective modulation wavelength of the multilayer and these parameters will affect the Raman spectra. In Fig. 5 we plot the optical-phonon band of TiN coatings deposited at various bias voltages. In this case there is a clear shift in the position of the optical-phonon band to higher frequencies, indicating that an increase in the compressive stress within the coatings occurred with an increase in the bias voltage. There is also a

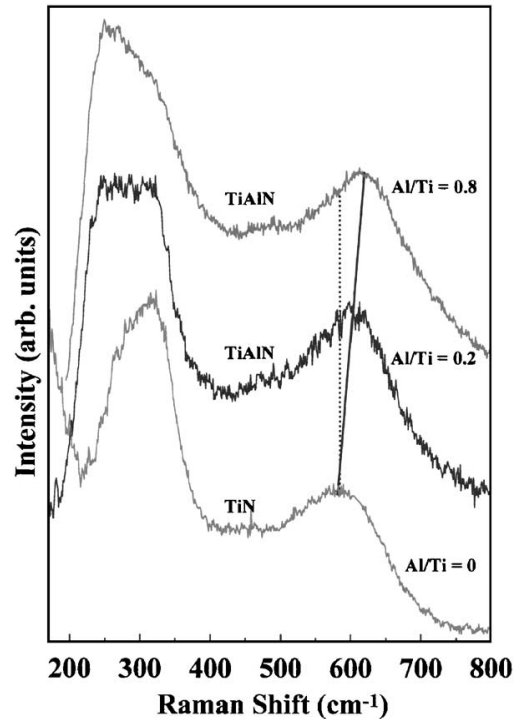

FIG. 6. Raman spectra of approximately 1400 - $\AA$-thick as-deposited TiAlN coatings deposited at various $\mathrm{Al}$ concentrations. Other conditions such as substrate temperature, nitrogen flow rate, substrate bias, etc., were same for all the coatings.

significant change in the bandwidth with increasing bias voltage. The increase in the bandwidth with substrate bias can be explained by a decrease in the grain size. These changes imply substantial variations in lattice ordering with a greater preponderance of lattice defects present at the higher bias voltages. In another set of experiments, we prepared TiAlN coatings at various Al concentrations. The relative $\mathrm{Al}$ concentration was measured using EDAX analysis. It is known that incorporation of $\mathrm{Al}$ in the face-centered-cubic TiN structure on Ti sites leads to deformation and strengthening of the crystal structure of the coating and consequently stress is larger in TiAlN as compared to TiN. ${ }^{10}$ This was confirmed by Raman spectra of TiAlN coatings deposited at various $\mathrm{Al}$ concentrations. In Fig. 6 we show typical Raman spectra of approximately 1400 - $\AA$-thick TiAlN coatings deposited at two $\mathrm{Al}$ concentrations along with the Raman spectrum of TiN. All the other deposition conditions such as nitrogen flow rate, substrate temperature, and substrate bias were kept the same. Furthermore, Al concentrations were chosen in such a way that only the cubic phase of TiAlN was formed and no other phases such as $\mathrm{Ti}_{2} \mathrm{AlN}$ or AlN were formed. A gradual shift in the position of the optical-phonon band can be seen with an increase in the $\mathrm{Al}$ content in the TiN coating, thus confirming that $\mathrm{Al}$ incorporation in TiN leads to compressive stress in the coating. Both the above observations demonstrate that the Raman measurements, in the present study, are accurate and consistent.

In order to understand the origin of the shift in the optical-phonon band of TiAlN/TiN multilayers with modulation wavelength we prepared approximately 1400 - $\AA$-thick TiAlN/TiN multilayer coatings at different substrate temperatures, while keeping the modulation wavelength the same (about $80 \AA$ ). In Fig. 7 we show the Raman spectra of TiAlN/TiN multilayer coatings deposited at 32, 300, and $400{ }^{\circ} \mathrm{C}$. The optical-phonon band shifts to higher frequencies with an increase in the substrate temperature. However, 


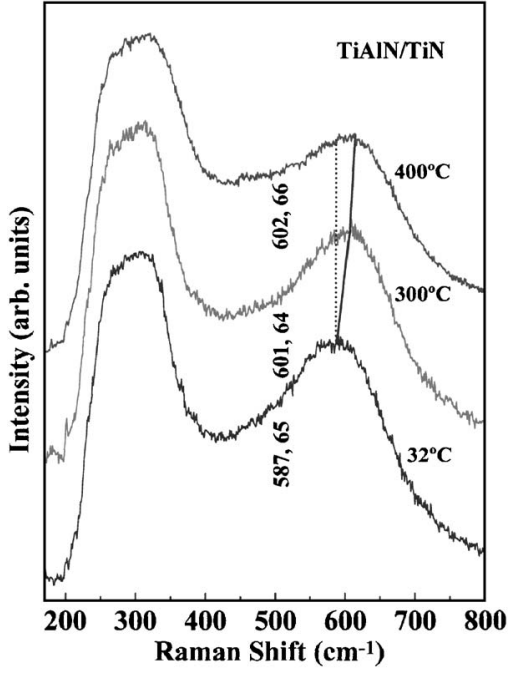

FIG. 7. Raman spectra of approximately 1400- $\AA$-thick TiAlN/TiN multilayer coatings deposited at various substrate temperatures. The modulation wavelength was about $80 \AA$. Other conditions such as nitrogen flow rate, substrate bias, etc., were same for all the coatings.

no significant shift was observed in $\mathrm{TiN} / \mathrm{NbN}$ multilayer coatings deposited under similar conditions at 45,200, and $400{ }^{\circ} \mathrm{C}$ (Fig. 8). Similarly, about 1400 - $\AA$-thick TiN coatings deposited at 45 and $300{ }^{\circ} \mathrm{C}$ did not show a significant shift in the position of the optical-phonon band (Fig. 9). This may indicate that the observed shift in TiAlN/TiN multilayers is primarily due to interfacial diffusion during the deposition. To confirm the effect of interdiffusion on the shift in the optical-phonon band we deposited a TiAlN/TiN multilayer coating $(\Lambda=80 \AA)$ at room temperature and subsequently annealed $\left(T_{A}\right)$ it at $400{ }^{\circ} \mathrm{C}$ under very high-vacuum conditions $\left(2.0 \times 10^{-4} \mathrm{~Pa}\right)$ for $4 \mathrm{~h}$. The XRD data showed that no other phases were formed as a result of annealing of TiAlN/TiN multilayers. The Raman spectra of as-deposited and annealed TiAlN/TiN multilayer coatings are shown in Fig. 10. A shift

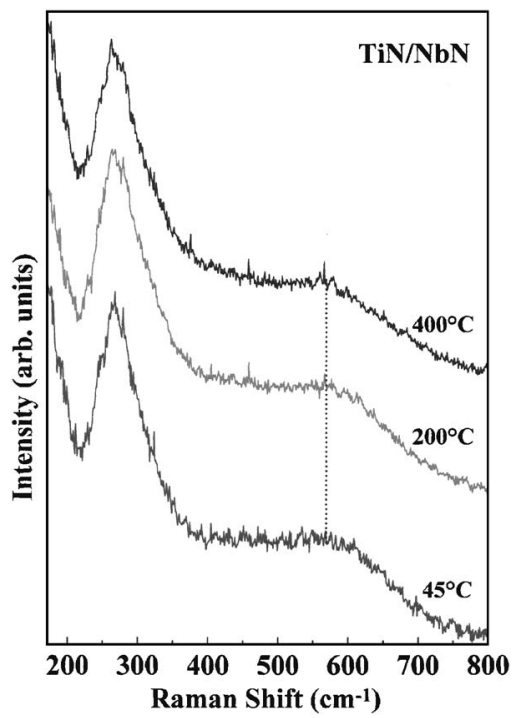

FIG. 8. Raman spectra of approximately 1400 - $\AA$-thick $\mathrm{TiN} / \mathrm{NbN}$ multilayer coatings deposited at various substrate temperatures. The modulation wavelength was about $50 \AA$ A Other conditions such as nitrogen flow rate, substrate bias, etc., were same for all the coatings.

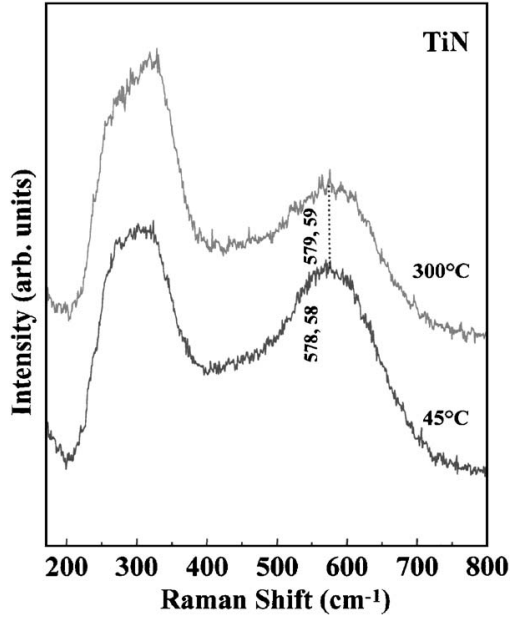

FIG. 9. Raman spectra of approximately 1400 - $\AA$-thick TiN coatings deposited at 45 and $300{ }^{\circ} \mathrm{C}$ substrate temperatures. Other conditions such as nitrogen flow rate, substrate bias, etc., were same.

in the position of the optical-phonon band is observed for the annealed coating, confirming that the observed shift in TiAlN/TiN multilayers is primarily due to interfacial diffusion. In general, annealing of the coatings above the deposition temperature heals out defects in the coating. ${ }^{42}$ One should therefore expect a shift in the position of the opticalphonon band to lower frequencies and a decrease in the FWHM with annealing. This behavior is represented in Fig. 11 , wherein we plot a portion of the Raman spectra of asdeposited TiN coating (substrate temperature $=300{ }^{\circ} \mathrm{C}$ ) and TiN coating annealed at $800{ }^{\circ} \mathrm{C}$ under high-vacuum conditions for $60 \mathrm{~min}$. The Raman data presented in Fig. 10, however, suggest that in the case of TiAlN/TiN multilayer coatings annealing introduced more defects than healing them out because of interfacial diffusion.

The effect of interface between two coexisting phases on the diffusion has been discussed by Cahn and Hilliard. ${ }^{43}$ Subsequently, for thin metallic multilayers $\mathrm{Greer}^{44}$ modified the Cahn and Hilliard model of a continuum solution. It has been shown that the effective interdiffusivity $D_{\Lambda}^{\prime}$ in a multilayer of a modulation wavelength $\Lambda$ is modified as ${ }^{44}$

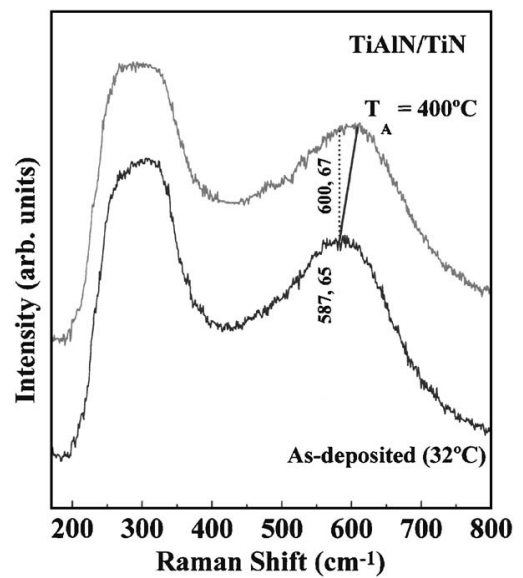

FIG. 10. Raman spectra of approximately $1400 \AA$ thick (a) as-deposited TiAlN/TiN multilayer coating and (b) as-deposited multilayer coating vacuum annealed at $400^{\circ} \mathrm{C}$. The modulation wavelength was about $80 \AA$. 


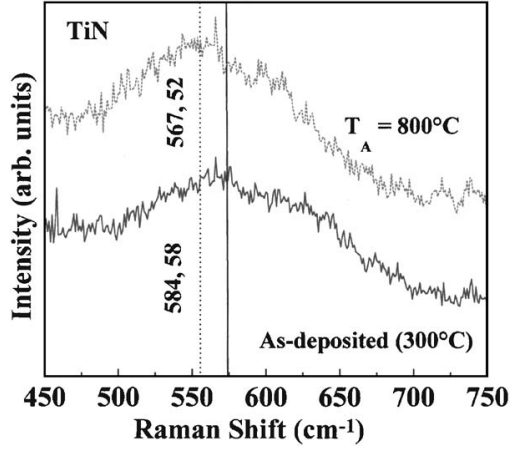

FIG. 11. Raman spectra of $1.5 \mu \mathrm{m}$ thick (a) as-deposited and (b) annealed TiN coatings. The substrate temperature was $300{ }^{\circ} \mathrm{C}$. A downward shift in the position of the optical phonon band was observed, which was attributed to relaxation of the compressive stress.

$$
D_{\Lambda}^{\prime}=D^{\prime}\left[1+\left\{8 \pi^{2} / \Lambda^{2} f^{\prime \prime}\right\} k\right]
$$

where $D^{\prime}$ is the normal microscopic interdiffusivity, $f^{\prime \prime}$ is the second derivative of the free energy with respect to composition, and $k$ is the gradient energy coefficient. Equation (1) shows that the deviation of $D_{\Lambda}^{\prime}$ from $D^{\prime}$ is significant only for very small $\Lambda$. In other words, there will be more interdiffusion between the layers if the layer thicknesses are very small. Equation (1) needs to be further modified for multicomponent transition-metal nitride multilayers because of the fact that the interfaces in these materials become more complex due to different diffusivities of $\mathrm{N}$ and other constituent elements such as $\mathrm{Ti}, \mathrm{Al}$, and $\mathrm{Nb}$. In addition, coherency strain also enhances effective interdiffusivity in multilayer coatings. ${ }^{45}$ The interdiffusion of nitride layers in a multilayer results in modification of the composition profile. ${ }^{46}$ For miscible materials (such as TiN, NbN, and TiAlN), due to intermixing during deposition, the superlattice interfaces are expected to have a nonzero width. Although, the interface width values for superlattices have not been quantitatively determined it has been shown that the interface width $w$ can be given by ${ }^{47}$

$$
w=\left(C_{\mathrm{A}}-C_{\mathrm{B}}\right) / C^{\prime},
$$

where $C_{\mathrm{A}}$ and $C_{\mathrm{B}}$ are the compositions of layers $\mathrm{A}$ and $\mathrm{B}$, respectively and $C^{\prime}$ is the composition gradient. For large values of $\Lambda$, the modulation becomes trapezoidal and the interface width is very small. However, for small values of $\Lambda$ the modulation becomes sawtooth and the interface width becomes relatively large. Simulations of XRD data of singlecrystal TiN/NbN superlattices deposited at $700{ }^{\circ} \mathrm{C}$ yielded $w \cong 1.0 \mathrm{~nm} .{ }^{48}$ This interface broadening was mainly attributed to the substrate temperature and ion bombardment mixing during bias sputter deposition. ${ }^{49}$ In our case the substrate temperature was only $300{ }^{\circ} \mathrm{C}$ and, therefore, we expect $w$ to be very small for TiN/NbN multilayer system. As the other deposition conditions were the same for both TiAlN/TiN and $\mathrm{TiN} / \mathrm{NbN}$ multilayers, the Raman data suggest broad interfaces for the TiAlN/TiN multilayers and relatively sharp interfaces for the TiN/NbN multilayers. It has been predicted that the superlattice hardness/strength depends strongly on the interface width for small $\Lambda .{ }^{47,50}$

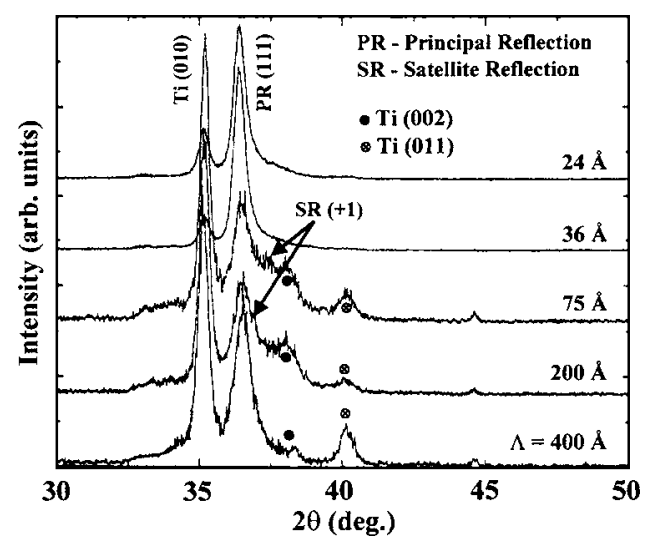

FIG. 12. XRD data of TiAlN/TiN multilayer coatings deposited at various modulation wavelengths.

\section{B. X-ray-diffraction data of TiAIN/TiN and TiN/NbN multilayers}

Figure 12 shows the XRD patterns of about 1.5- $\mu \mathrm{m}$-thick TiAlN/TiN multilayer film deposited at various modulation wavelengths. The structure of the multilayer was composed of a (111) principal reflection (PR). For $\Lambda$ $=75$ and $200 \AA$ the principal reflection was flanked by a very weak first-order positive satellite reflection (SR), which was indicative of weak superlattice formation under these conditions. Various Ti reflections seen in the figure actually originate from the $\mathrm{Ti}$ interlayer, which was used for improved adhesion of the coating. The intensities of other reflections such as (200), (220), and (222) were very low, indicating that TiAlN/TiN multilayer films exhibited $\{111\}$ texture. The position of the (111) peak remained almost unaffected with an increase in the modulation wavelength. Contrary to TiAlN/TiN, about $1.5-\mu \mathrm{m}$-thick TiN/NbN multilayers exhibited well-developed first-order negative satellite reflections along the principal reflection. The XRD data of TiN/NbN multilayers deposited at different modulation wavelengths are shown in Fig. 13. Superlattice structure was clearly seen for all the films. Furthermore, the XRD data showed that all TiN/NbN multilayers exhibited $\{111\}$ texture. Detailed analysis of the XRD data showed that all TiAlN/TiN and TiN/NbN multilayer coatings exhibited B1 $\mathrm{NaCl}$ structure. The presence of a very weak satellite reflec-

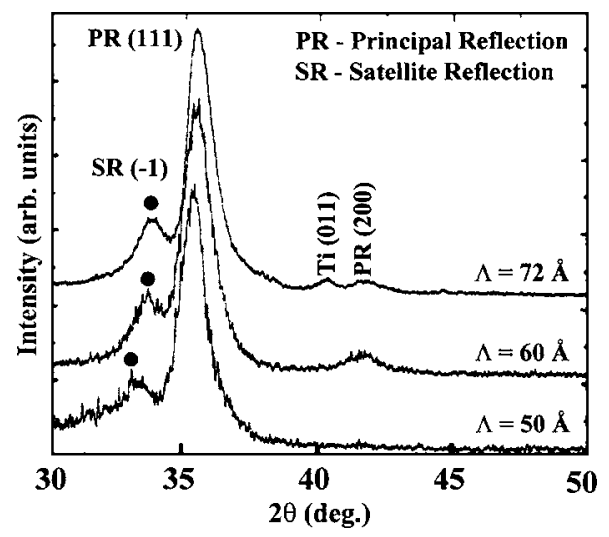

FIG. 13. XRD data of TiN/NbN multilayer coatings deposited at various modulation wavelengths. 


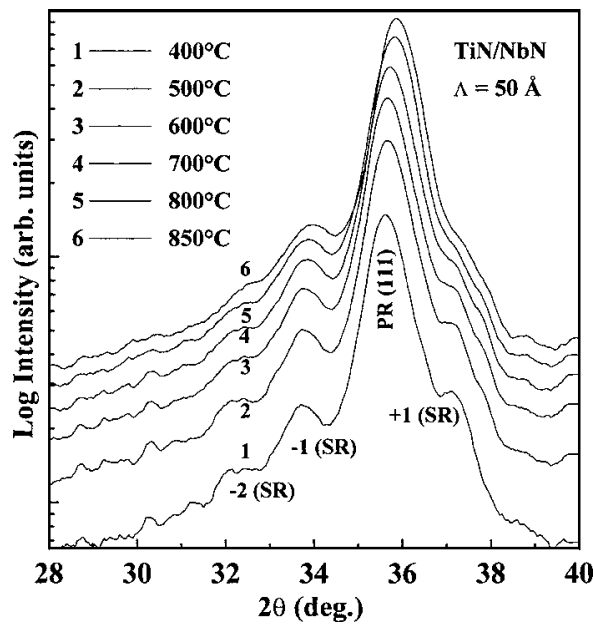

FIG. 14. High-temperature $\mathrm{XRD}$ data of a $\mathrm{TiN} / \mathrm{NbN}$ superlattice coating annealed at $400,500,600,700,800$, and $850{ }^{\circ} \mathrm{C}$. The modulation wavelength was $50 \AA$.

tion in TiAlN/TiN multilayers as compared to TiN/NbN system further indicates that the interfaces were very broad in the former case.

The Raman spectra of TiAlN/TiN multilayers deposited at higher substrate temperatures showed a shift in the opticalphonon band to higher frequencies (Fig. 7), whereas no significant shift was observed for TiN/NbN coatings deposited at higher substrate temperatures (Fig. 8). This indicated that the self-interdiffusion was minimal in TiN/NbN multilayers. To confirm this we annealed about $1.5-\mu \mathrm{m}$-thick TiN/NbN multilayer film $(\Lambda=50 \AA)$ under high-vacuum conditions and recorded in situ high-temperature XRD data. Typical high-temperature XRD plots obtained from the TiN/NbN multilayer sample annealed at 400,500,600,700,800, and $850^{\circ} \mathrm{C}$ are shown in Fig. 14. All the plots exhibited a strong (111) principal reflection. First- and second-order negative satellites and even first-order positive satellite were seen along the principal reflection. Further analysis of the hightemperature XRD data indicated that the position of the (111) principal reflection shifts to higher $2 \theta$ values. This may be attributed to stress relaxation as a result of annealing. No significant change in the intensity of first-order satellite reflection was observed up to $700{ }^{\circ} \mathrm{C}$, however, it decreased significantly for $T_{\mathrm{A}}>700{ }^{\circ} \mathrm{C}$. Similarly, FWHM of the SR peak increased considerably for $T_{\mathrm{A}} \geqslant 700{ }^{\circ} \mathrm{C}$. Both these observations indicate that the coating perfectly retained its superlattice character up to $700{ }^{\circ} \mathrm{C}$ and subsequently started degrading marginally. The position of the satellite reflection did not change with annealing temperature, indicating no change in the modulation wavelength. Hence, variations in the layer thicknesses were minimal during annealing. Lopez et $a l^{51}$ also observed that annealing of single-crystal $\mathrm{TiN} / \mathrm{NbN}$ multilayers caused almost no intermixing up to $700{ }^{\circ} \mathrm{C}$, while the hardness, the adhesion/cohesion, and the structure remained unaffected. These analyses suggest better thermal stability (with respect to interdiffusion) of $\mathrm{TiN} / \mathrm{NbN}$ multilayers as compared to TiAlN/TiN multilayers.

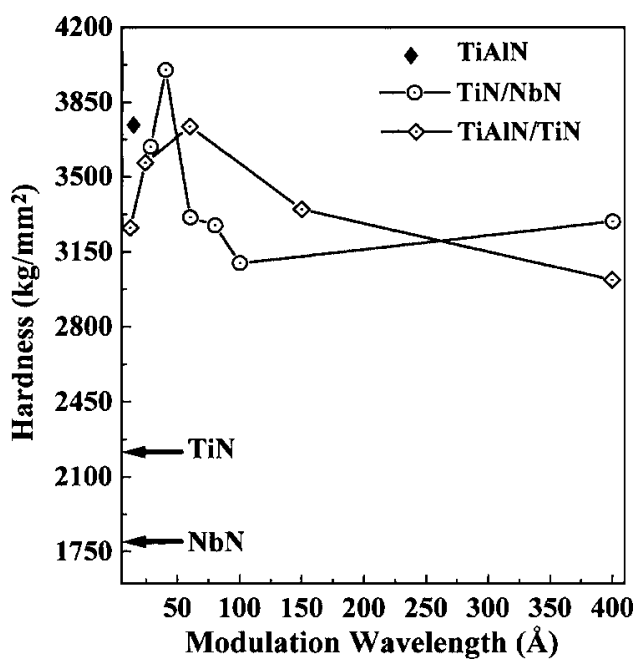

FIG. 15. Variations of nanoindentation hardnesses of TiAlN/TiN and $\mathrm{TiN} / \mathrm{NbN}$ multilayer coatings with modulation wavelength. Also, shown are the hardnesses of single layer TiAlN, TiN, and $\mathrm{NbN}$ coatings.

\section{Nanoindentation data of TiAIN/TiN and TiN/NbN multilayers}

Now we briefly discuss the mechanical properties, especially, nanoindentation hardness of TiAlN/TiN and $\mathrm{TiN} / \mathrm{NbN}$ multilayers. The variation of nanoindentation hardness of about $1.5-\mu \mathrm{m}$-thick TiAlN/TiN multilayer films with modulation wavelength is shown in Fig. 15. For TiAlN/TiN multilayers, the peak hardness occurred at $\Lambda$ $=60 \AA$ and the maximum hardness was $3700 \mathrm{~kg} / \mathrm{mm}^{2}$. The hardness values of TiAlN and TiN films deposited under similar conditions were approximately 3800 and $2400 \mathrm{~kg} / \mathrm{mm}^{2}$, respectively. The maximum hardness of TiAlN/TiN multilayer films was slightly higher than the value of the rule of mixture, which for TiAlN-TiN is $3100 \mathrm{~kg} / \mathrm{mm}^{2}$. For a comparison we also show the variation of nanoindentation hardness of about 1.5- $\mu \mathrm{m}$-thick TiN/NbN multilayers with modulation wavelength in Fig. 15. For TiN/NbN system, the peak hardness occurred at $\Lambda$ $=50 \AA$ and the maximum hardness was $4000 \mathrm{~kg} / \mathrm{mm}^{2}$, whereas the hardness values of $\mathrm{TiN}$ and $\mathrm{NbN}$ coatings were approximately 2400 and 1800 , respectively. The maximum hardness obtained for the $\mathrm{TiN} / \mathrm{NbN}$ multilayer was about two times the value of the rule of mixture, which for TiN$\mathrm{NbN}$ is $2100 \mathrm{~kg} / \mathrm{mm}^{2}$.

Compared to the average hardnesses of TiN and TiAlN coatings, a small enhancement in the maximum hardness of TiAlN/TiN multilayers was observed in the present study. However, a significant improvement in the hardness for $\mathrm{TiN} / \mathrm{NbN}$ multilayers was observed as compared to the ruleof-mixture value. Similar results have been reported in the literature. ${ }^{1,8-11}$ This is not surprising considering the fact that the enhancement in the hardness of nanolayered multilayer coatings is mainly caused by (a) the difference in the shear moduli of the constituent layers and (b) the interface width. ${ }^{47}$ It has been reported that the coherency strain effects do not contribute significantly for the hardness enhancement in nanolayered transition-metal nitride multilayer coatings. ${ }^{52,53}$ For TiN and $\mathrm{NbN}$ the shear moduli differ significantly (i.e., 
192 and $142 \mathrm{GPa}$ for TiN and $\mathrm{NbN}$, respectively). Although reliable shear modulus data of TiAlN are lacking our nanoindentation data showed almost similar values of elastic moduli for TiN and TiAlN coatings deposited under identical conditions, suggesting very similar shear moduli for TiN and TiAlN. Furthermore, the Raman data showed that the interface width was very large for TiAlN/TiN multilayer coatings. Because of the above reasons it is expected that the hardness of $\mathrm{TiN} / \mathrm{NbN}$ multilayers should be very high as compared to the rule of mixture, which is not true for TiAlN/TiN multilayers. The interdiffusion between the layers, therefore, removes the precondition for the hardness enhancement in nanolaminates, which shows a reciprocal dependence upon the interface width, as discussed in the literature. ${ }^{47}$

\section{CONCLUSIONS}

The optical-phonon band of TiAlN/TiN multilayers shifted to higher frequencies with a decrease in the modulation wavelength and FWHM of the optical-phonon band did not change significantly with $\Lambda$. No such shift in the position of the optical-phonon band was observed for TiN/NbN multilayers. The optical-phonon band of TiAlN/TiN multilayers $(\Lambda=80 \AA)$ also shifted to higher frequencies with an increase in the substrate temperature; however, single-layer TiN and TiN/NbN multilayers did not exhibit any such shift. Furthermore, vacuum annealing of TiAlN/TiN multilayers $(\Lambda$ $=80 \AA$ ) at $400{ }^{\circ} \mathrm{C}$ resulted in the shift in the position of the optical-phonon band to higher frequencies. This observed shift in the position of the optical-phonon band in TiAlN/TiN multilayers is attributed to interdiffusion between the layers during deposition. For TiN/NbN system, however, the in situ high-temperature XRD data confirmed that the interdiffusion was minimal up to $700{ }^{\circ} \mathrm{C}$. The interdiffusion deteriorated the superlattice quality at low $\Lambda$. The XRD showed weakly resolved satellite reflections for TiAlN/TiN multilayers and well-developed satellite reflections for TiN/NbN multilayers. The interdiffusion also affected the maximum enhancement in the hardness of the coatings. The maximum hardness for TiN/NbN multilayers was much higher than the rule-of-mixture value, whereas no significant improvement in the hardness was observed for TiAlN/TiN multilayers.

\section{ACKNOWLEDGMENTS}

The authors would like to thank Dr. Anjana Jain for recording XRD data. Dr. Sharat Chandra is thanked for recording high-temperature XRD data. Siju's help is acknowledged for recording Raman spectroscopy data. The authors thank Director, NAL for giving permission to publish these results. This work was supported by the Department of Science and Technology, New Delhi and the Council of Scientific and Industrial Research, New Delhi (Grant No. CMM 0022), India.

${ }^{1}$ H. C. Barshilia and K. S. Rajam, Surf. Coat. Technol. 183, 174 (2004).

${ }^{2}$ H. C. Barshilia, M. S. Prakash, A. Poojari, and K. S. Rajam, Thin Solid Films 460, 133 (2004).

${ }^{3}$ M. Larsson, M. Bromark, P. Hedenqvist, and S. Hogmark, Surf. Coat.
Technol. 91, 43 (1997).

${ }^{4}$ H. Ljungcrantz, E. Engstrom, L. Hultman, M. Olsson, X. Chu, M. S. Wong, and W. D. Sproul, J. Vac. Sci. Technol. A 16, 3104 (1998).

${ }^{5}$ W. D. Munz, J. Vac. Sci. Technol. A 4, 2717 (1986).

${ }^{6}$ H. Ichimura and A. Kawana, J. Mater. Res. 8, 1093 (1993).

${ }^{7}$ D. McIntyre, J. E. Greene, G. Hakansson, J. E. Sundgren, and W. D. Munz, J. Appl. Phys. 67, 1542 (1990).

${ }^{8}$ J. H. Hsieh, C. Liang, C. H. Yu, and W. Wu, Surf. Coat. Technol. 108109, 132 (1998).

${ }^{9}$ K. N. Andersen, E. J. Bienk, K. O. Schweitz, H. Reitz, J. Chevallier, P. Kringhoj, and J. Bottiger, Surf. Coat. Technol. 123, 219 (2000).

${ }^{10}$ E. Zoestbergen, N. J. M. Carvalho, and J. T. M. De Hosson, Surf. Eng. 17, 29 (2001).

${ }^{11}$ F.-R. Weber, F. Fontaine, M. Scheib, and W. Block, Surf. Coat. Technol. 177-178, 227 (2004).

${ }^{12}$ B. Jusserand, F. Alexandre, D. Paquet, and G. Le Roux, Appl. Phys. Lett. 47, 301 (1985).

${ }^{13}$ P. V. Santos, M. Hundhausen, L. Ley, and C. Viczian, J. Appl. Phys. 69, 778 (1991)

${ }^{14}$ M. Yano, T. Utatsu, Y. Iwai, and M. Inoue, J. Cryst. Growth 150, 868 (1995).

${ }^{15}$ G. Armelles, P. Castrillo, P. D. Wang, C. M. Sotamayor Torres, N. N. Ledenstov, and N. A. Bert, Solid State Commun. 94, 613 (1995).

${ }^{16}$ P. D. Persans, A. F. Rupport, B. Abeles, and T. Tiedje, Phys. Rev. B 32, 5558 (1985).

${ }^{17}$ N. Georgiev and T. Mozume, Appl. Surf. Sci. 159-160, 520 (2000).

${ }^{18}$ P. V. Santos and L. Ley, Phys. Rev. B 36, 3325 (1987).

${ }^{19}$ S. Nakashima, Y. Nakakura, H. Fujiyasu, and K. Mochizuki, Appl. Phys. Lett. 48, 236 (1986).

${ }^{20}$ F. Cerdeira, A. Pinczuk, J. C. Bean, B. Batlogg, and B. A. Wilson, Appl. Phys. Lett. 45, 1138 (1984).

${ }^{21}$ M. Yano, M. Okuizmi, Y. Iwai, and M. Inoue, J. Appl. Phys. 74, 7472 (1993).

${ }^{22}$ S. Nakashima, A. Wada, H. Fujiyasu, M. Aoki, and H. Yang, J. Appl. Phys. 62, 2009 (1987).

${ }^{23}$ D. Nesheva, I. P. Kotsalas, C. Raptis, and E. Vateva, J. Non-Cryst. Solids 224, 283 (1998).

${ }^{24}$ B. Schreder, T. Kummell, G. Bacher, A. Forchel, G. Landwehr, A. Materny, and W. Kiefer, J. Cryst. Growth 214/215, 787 (2000).

${ }^{25}$ G. Lermann, T. Bischof, A. Materny, W. Kiefer, T. Kummell, G. Bacher, A. Forchel, and G. Landwehr, J. Appl. Phys. 81, 1446 (1997).

${ }^{26} \mathrm{~B}$. Jusserand and M. Cardona, Superlattices and Other Microstructures, Light Scattering in Solids Vol. V, edited by M. Cardona and G. Guntherodt (Springer, Berlin, 1989), p. 49.

${ }^{27}$ M. Franck, J.-P. Celis, and J. R. Roos, J. Mater. Res. 10, 119 (1995).

${ }^{28}$ H. C. Barshilia and K. S. Rajam, J. Mater. Res. 19, 3196 (2004).

${ }^{29}$ E. Vancoille, B. Blanpain, Y. Xingpu, J. P. Celis, and J. R. Roos, J. Mater. Res. 9, 992 (1994).

${ }^{30}$ N. Muraki, V. Sergo, G. Pezzotti, G. Katagiri, S. Meriani, and T. Nishida, Appl. Spectrosc. 51, 1761 (1997).

${ }^{31}$ M. Bernard, A. Deneuville, O. Thomas, P. Gergaud, P. Sandstrom, and J. Birch, Thin Solid Films 380, 252 (2000).

${ }^{32}$ C. P. Constable, J. Yarwood, and W. D. Munz, Surf. Coat. Technol. 116119, 115 (1999).

${ }^{33}$ C. P. Constable, D. B. Lewis, J. Yarwood, and W. D. Munz, Surf. Coat. Technol. 184, 291 (2004).

${ }^{34}$ H. C. Barshilia, M. S. Prakash, A. Jain, and K. S. Rajam, Vacuum 77, 169 (2005).

${ }^{35}$ W. Spengler and R. Kaiser, Solid State Commun. 18, 881 (1976).

${ }^{36}$ H. Richter, Z. P. Wang, and L. Ley, Solid State Commun. 39, 625 (1981).

${ }^{37}$ I. H. Campbell and P. M. Fauchet, Solid State Commun. 58, 739 (1986).

${ }^{38}$ W. Spengler, R. Kaiser, and H. Bilz, Solid State Commun. 17, 19 (1975).

${ }^{39}$ I. Petrov, L. Hultman, U. Helmersson, J.-E. Sundgren, and J. E. Greene, Thin Solid Films 169, 299 (1989).

${ }^{40}$ H. Ljungcrantz, L. Hultman, J. E. Sundgren, and L. Karlsson, J. Appl. Phys. 78, 832 (1995).

${ }^{41}$ L. Hultman, U. Helmersson, S. A. Barnett, J.-E. Sundgren, and J. E. Greene, J. Appl. Phys. 61, 552 (1987).

${ }^{42}$ I. Kosacki, T. Suzuki, H. U. Anderson, and P. Colomban, Solid State Ionics 149, 99 (2002).

${ }^{43}$ J. W. Cahn and J. E. Hilliard, J. Chem. Phys. 28, 258 (1958).

${ }^{44}$ A. L. Greer, J. Magn. Magn. Mater. 126, 89 (1993).

${ }^{45}$ E. M. Philofsky and J. E. Hilliard, J. Appl. Phys. 40, 2198 (1969). 
${ }^{46}$ L. Hultman, Vacuum 57, 1 (2000).

${ }^{47}$ X. Chu and S. A. Barnett, J. Appl. Phys. 77, 4403 (1995).

${ }^{48}$ A. Madan, P. Yashar, M. Shinn, and S. A. Barnett, Thin Solid Films 302, 147 (1997).

${ }^{49}$ X. Chu, S. A. Barnett, M. S. Wong, and W. D. Sproul, Surf. Coat. Technol. 57, 13 (1993).
${ }^{50}$ J. E. Krzanowski, Scr. Metall. Mater. 25, 1465 (1991).

${ }^{51}$ S. Lopez, M. S. Wong, and W. D. Sproul, J. Vac. Sci. Technol. A 13, 1644 (1995).

${ }^{52}$ M. Shinn and S. A. Barnett, Appl. Phys. Lett. 64, 61 (1994).

${ }^{53}$ P. B. Mirkarimi, S. A. Barnett, K. M. Hubbard, T. R. Jervis, and L. Hultman, J. Mater. Res. 9, 1456 (1994). 